\title{
Research on Internet Consumer Financial Products Usage Intention-Taking College Students as an Example
}

\author{
Yexin Cai \\ School of Management, Jinan University, Guangzhou, China \\ Email: 497996805@qq.com
}

How to cite this paper: Cai, Y. X. (2017). Research on Internet Consumer Financial Products Usage Intention-Taking College Students as an Example. Journal of Financial Risk Management, 6, 375-388. https://doi.org/10.4236/jfrm.2017.64027

Received: November 21, 2017

Accepted: December 17, 2017

Published: December 20, 2017

Copyright $\odot 2017$ by author and Scientific Research Publishing Inc. This work is licensed under the Creative Commons Attribution International License (CC BY 4.0).

http://creativecommons.org/licenses/by/4.0/

\section{c) (i) Open Access}

\begin{abstract}
With the rise of Internet consumer finance, it has greatly promoted the prosperity of the stage consumption market, and the college students group is a market with great development space and untapped market. In this research background, this article combines the technology acceptance model and the rational acceptance model, and introduces consumer innovation and perceived risk to explore the influence of consumers on the willingness of ecommerce Internet consumer financial products. The study found that perceived usefulness and willingness to use had a significant positive correlation, and that perceived risk and willingness to use had a significant negative correlation. Perceived ease of use and subjective norms have a significant positive effect on perceived usefulness; Consumer innovation and perceived ease of use have significant positive impact, and consumers' innovation and perceived risk have significant negative impact. The conclusions of this study enrich the study of willingness to use, and put forward relevant marketing strategies for enterprises to promote and occupy market share.
\end{abstract}

\section{Keywords}

Usage Intention, Perceived Risk, Consumer Innovativeness, Technology Acceptance Model, Internet Consumer Finance

\section{Research Background}

With the rapid transformation and rapid development of China's economy, the proportion of national consumption in the national economic structure has gradually increased, and people's consumption ability has been continuously improved. Under this background, China's consumer financial market is booming 
and developing rapidly. At the same time, the constant innovation of Internet technology has greatly promoted the development of consumer finance. However, there are many differences between Internet consumer finance and offline traditional consumer finance, such as the way of consumption, the platform for consumption and the payment method. The current domestic Internet finance is still in its initial stage of development. Kotler (2000) suggests that enterprises should focus on the strategy of creating and providing value for customers. At present, the Internet consumer finance is in the early stage of development and there is still a great development space, so it is necessary to understand consumers' perception and willingness to use its products. At the same time, there are few researches on the use intention of Internet consumer financial products. Such research is of great significance to the adoption and promotion of new technology products. Therefore, this paper will study the composition of the influence factors of consumption financial use intention, and which factors affect users' use intention most. Based on the characteristics of the research object, this paper integrates the planned behavior theory and the theoretical model of technology acceptance, and then introduces the perceived risk and consumer innovation to study the consumer behavior so as to enhance the explanatory power of the model. This is of great significance to help enterprises improve their products, and promote the Internet consumer financial enterprises to enhance market competitiveness.

\section{Literature Review}

\subsection{Internet Consumer Finance}

At present, consumer finance has not developed independent research theory system, and the concept of consumer finance has not yet formed a unified academic definition. In the previous studies, Wang et al. (2010) argue that consumer finance can be interpreted as the majority of financial activities that have been consumed, namely can be understood as some financial institutions or enterprises in the process of consumer spending to provide some financial products or services, such as consumer loans. Liu (2011) proposed that consumer finance is a form of providing consumer loans or credit loans to individuals or groups through multiple dimensions and paths, Consumer finance enables consumers to consume in advance, which is conducive to promote and enhance the current market demand.

\subsection{User Acceptance and Usage Model}

Consumers' willingness to use Internet consumer finance products can be understood as consumers' willingness to use in information technology innovation. At present, rational behavior theory and technology acceptance model have been verified in many empirical studies on the willingness of consumer information technology. Therefore, this article will elaborate and compare the above model. 


\subsubsection{Rational Behavior Theory}

Fishbein and Ajzen (1975) put forward the theory of rational behavior, the theory from individual beliefs, attitudes, and behavior intention three dimensions explain and determine consumers' actual behavior, the path of influence is that individual attitudes and subjective norms, which will affect the behavior intentions and further influence the ultimate consumer behavior. Rational behavior theory is proposed in the case that the individual is rational, but there are many unpredictable risks in real life, which can hardly satisfy this condition. Therefore, Ajzen (1985) introduced the variable of perceived behavioral control in the theoretical model of rational behavior and proposed the planned behavior theory. The planned behavior theory takes individual limited rationality into account, and introduces the perception behavior control as a variable to measure uncontrollable factors. At present, the planned behavior theory has also been applied to the network banking (Fishbein, 1963), online system (Ajzen, 1985), mobile payment (Ajzen, 1991) and other related research. Therefore, the Internet consumer financial products mentioned in this paper are also applicable.

\subsubsection{Technical Acceptance Model}

The planned behavior theory is widely used in empirical research. However, due to its lack of concepts and standards of major variables, there is no unified measurement scale, so it is difficult to obtain model variables. On the basis of this, Davis (1989) proposed the technology acceptance model for the first time based on the user's willingness to accept information system. He proposed that perceived usefulness and perceived ease of use determine the attitude of consumers to science and technology, which in turn affects their behavioral intentions, which in turn determine consumer behavior. In addition, the external variables mainly affect the user's intention of behavior through two key factors: perceived usefulness and perceived ease of use. Venkatesh and Davis (2000) point out that the technology acceptance model is also the most important model to explain and predict the extent to which an information system is accepted and used by individuals. Venkatesh and Davis (2000) constructed the technology acceptance model 2, they joined the social influence variables and relevant variables useful in the cognitive system into the technology acceptance model to explain the extent to which perceived usefulness has an impact on the willingness to use. Among them, social influence variables include subjective norm, initiative and image; Relevant variables that are useful to the cognitive system include work correlation, output quality, results, and perceived ease of use. At present, the technology acceptance model is also widely used in the research fields of online shopping (Klopping \& Kiuney, 2004) and mobile commerce (Deng \& Lu, 2007; $\mathrm{Xu}$ et al., 2011), and it is still developing.

\subsection{Perceived Risk Theory}

Bauer (1960) first put forward the perception risk, which refers to the degree of uncertainty and risk of the consumers' subjective feeling when making purchasing 
decisions. Jacoby and Kaplan (1972) divided perceived risk into five dimensions: financial risk, functional risk, physical risk, psychological risk and social risk. Compared with traditional trading methods, the risks of internet-based electronic transactions are also related to the risks caused by the online trading environment. In the study of network services, Featherman \& Pavlou (2003) divided perceived risk into performance risk, financial risk, time risk, psychological risk, social risk and privacy risk. In the study of e-commerce, Park et al. (2004) divided perceived risk into perceived risk to online transaction activity and perceived risk to product or service. The perceived risk to product or service is similar to the traditional six-dimensionality, and the perceived risk to online trading environment includes four dimensions of security, privacy, non-repudiation and integration.

The research object of this paper is the Internet consumer financial products. In the process of using the product, the user's personal information and transaction data are transmitted through the network. According to the various risks faced by consumers in the network environment, this paper selects financial risk and privacy risk as the main factors that affect the use of Internet consumer financial products.

\subsection{Consumer Innovativeness}

Consumer innovativeness is a concept that scholars founded during the process of studying the theory of innovation diffusion. Early research mainly adopts psychological research methods, by using the time point of the new things or ideas to distinguish. Rogers \& Shoemaker (1971) argued that consumer innovation is the degree to which an individual has earlier adopted an innovation in society than others. Midgley \& Dowlingzui (1978) first systematically studied consumer innovation, dividing innovation into innate and practical innovations. Hofstede and Wedel (1999) argued that innate innovation is a propensity to buy new, different products or brands without maintaining previous choices or patterns of consumption. With the development of the innovation diffusion architecture, the concept of practical innovation has been deeply studied, especially in the field of diffusion research of IT and new product market. Liu (2011) believes that the actual innovation includes the actual purchase of new products and innovative information search for new products.

Based on the technology acceptance model, Huang et al. (2008) studied consumer adoption of mobile services based on the innovation of individuals, external influences and perceived financial costs. In addition, Lederer et al. (2000) perceived usefulness in the technology acceptance model corresponds to the relative superiority in the innovation diffusion theory, and perceived ease of use corresponds to the complexity in the innovation diffusion theory. Therefore, this article attempts to explore the relationship between consumer innovation and perceived ease of use and perceived usefulness.

The emergence of Internet financial products has led to a new mode of consumption payment. Choosing Internet consumer finance products, consumers 
are not only the adoption of information technology, but also the change of consumption concept and payment method. Therefore, on the basis of integrating the planned behavior theory and the theoretical model of technology acceptance, this paper puts forward a research model based on the characteristics of Internet consumer finance products and consumer innovation and perceived risk.

\section{Hypothesis}

\subsection{Hypotheses about Perceived Usefulness, Perceived Ease of Use, and Willingness to Use}

In the model of technology acceptance, perceived usefulness and perceived ease of use are two of the decisive factors influencing consumers' willingness to use, which can directly affect their willingness to use. At the same time, perceived ease of use can enhance perceived usefulness, thus acting on consumers' actual use or purchase behavior. Through literature research, we find that a large number of studies have verified the ability of technical acceptance models to predict and analyze consumer's willingness to use. Xu et al. (2011) combined the technology acceptance model with perceived service cost variables to analyze the influencing factors of college students' acceptance of mobile network services. They think that perceived usefulness and perceived ease of use have a significant direct impact on college students' adoption of mobile networks. Therefore, this paper proposes the following hypotheses:

H1a: Perceived usefulness has a significant positive impact on willingness to use.

H1b: Perceived ease of use has a significant positive effect on the willingness to use.

H1c: perceived ease of use has a significant positive effect on perceived usefulness.

\subsection{Hypotheses about Perceived Risk, Perceived Usefulness, and Purchase Intention}

Bauer argues that the consumer's purchasing decisions are influenced by the size of the perceived risk and that different consumers have different perceived risks for the same product or service. At the same time, perceived risk has also been proved to have a direct effect on the willingness to use in many studies. There is also the domestic and foreign scholars have explored the relationship between perceived risk and technology acceptance model. For example, Featherman and Pavlou (2003) verified that perceived risk has a significant negative impact on perceived usefulness through empirical research. Among them, time, economy and privacy risk will affect the willingness to use electronic services. Therefore, this paper proposes the following assumptions:

H2a: Perceived risk has a significant negative impact on willingness to use.

H2b: Perceived risk has a significant negative impact on perceived usefulness. 


\subsection{Hypotheses about Subjective Norms, Perceived Usefulness and Willingness to Use}

In the rational behavior theory and the planned behavior theory, subjective norms have an effect on the willingness to use. In the technology acceptance model 2, Venkatesh and Davis (2000) also believe that subjective norms will positively and directly affect technology' the willingness to use and perceived usefulness technology. Therefore, this study proposes the following assumptions:

H3a: Subjective norms have a significant positive effect on the willingness to use.

H3b: Subjective norms have a significant positive effect on perceived usefulness.

\subsection{Hypotheses about Consumer Innovativeness}

Chen (2011) found that consumers' innovative promoted consumers' purchase or use through empirical research. Hofstede and Wedel (1999) believe that the nature of innovation is to make different from the previous decision-making or consumption patterns to buy new products or brand. In addition, Lederer et al. (2000) argue that perceived usefulness in the technology acceptance model corresponds to the relative advantage of innovation diffusion theory, and perceived ease of use corresponds to the complexity of in the innovation diffusion theory. Moreover, Bauer (1960) believes that consumers will make use or purchase decisions based on the degree of perceived risk. At the same time, perceived risk also has a certain effect on the diffusion of innovation. Therefore, this paper proposes the following assumptions:

H4a: consumer innovativeness has a significant positive impact on perceived ease of use.

H4b: consumer innovativeness has a significant positive effect on perceived usefulness.

H4c: consumer innovativeness has a significant negative impact on perceived risk.

\section{Research Methods}

The research model of this paper not only integrates the planned behavior theory and technology acceptance model, but also combines the characteristics of Internet consumer financial products and consumer innovation and perceived risk. In this study, SPSS and AMOS are used as the main statistical tools to analyze the survey data to verify whether the research model and assumptions in this paper are valid, so as to improve the quantitative research of this paper.

\subsection{Experimental Subjects}

As a semi-social group, the consumption demand of college students is strong and diverse. College students have huge potential consumer demand, which is the target customer group that e-commerce enterprises and financial enterprises 
want to dig. His study takes college students as the research object and investigates their willingness to use Internet consumer finance products. Therefore, we choose students who have used "Jingdong baitiao" and "Ant check later" to take the questionnaire, and the unused college students will not be able to answer, and they will not be included in the sample size.

A total of 288 questionnaires were sent out in this study. 269 questionnaires were collected and the recovery rate was $93.40 \%$. The number of valid questionnaires is 257 , with an effective rate of $89.24 \%$. Overall sample recovery is relatively good.

\subsection{Scale Structure and Questionnaire Design}

Based on the previous research scale, the study variables are modified according to the characteristics of the research object in this paper. Finally, the measurement scale of this study was obtained. The main variables scale includes intention, perceived usefulness, perceived ease of use, perceived risk, subjective norms, and consumer innovativeness.

The questionnaire used in this study is divided into three parts: the introduction of e-commerce Internet consumer financial products and filling instructions, the main part of the questionnaire and the demographic characteristics of the subjects. The Likert scale of 7 points was used to measure the items. The whole experiment was completed in about 30 minutes.

\section{Data Analysis}

\subsection{Descriptive Statistics Analysis}

The research object is the college students who have not stable income source and used Internet consumer finance products. Using SPSS18.0 software, a descriptive statistical analysis was conducted on the demographic characteristics and the use of e-commerce internet consumer financial products of 257 valid samples.

Among the subjects surveyed, $49.81 \%$ were male and $50.1 \%$ were female. The distribution of grade is mainly concentrated in junior and senior, accounting for $29.57 \%$ and $38.52 \%$ respectively. In terms of monthly disposable amount, the largest number of 1000 - 3000 yuan, accounting for $57.59 \%$ of the total sample, followed by less than 1000 yuan, accounting for $28.79 \%$.In the electronic business platform shopping time, the most is more than 3 years, accounting for $53.7 \%$, followed by $1-3$ years, accounting for $36.19 \%$. The table of demographic characteristics is shown in Table 1.

The usage of e-commerce Internet consumer financial products is shown in Table 2. Among them, the duration of use of less than 3 months accounted for $63.42 \%, 3$ - 6 months accounted for $13.23 \%, 6$ - 12 months accounted for $14.01 \%$, more than a year accounted for $9.34 \%$. This shows that the use of consumer financial products by college students is still at an early stage. From the amount of use, the majority of the use amount is less than 500 yuan, accounting 
Table 1. Demographic characteristics table.

\begin{tabular}{cccc}
\hline Features & Type & Sample number (unit) & Percentage \\
\hline \multirow{2}{*}{ Gender } & Male & 128 & $49.81 \%$ \\
& Female & 129 & $50.19 \%$ \\
Grade & Freshman & 26 & $10.12 \%$ \\
& Sophomore & 56 & $21.79 \%$ \\
& Junior & 76 & $29.57 \%$ \\
& Senior & 99 & $38.52 \%$ \\
Discretionary amount per month & $<1000$ & 74 & $28.79 \%$ \\
& 1000 - 3000 & 148 & $57.59 \%$ \\
& 3000 - 5000 & 24 & $9.34 \%$ \\
& $>5000$ & 11 & $4.28 \%$ \\
& Less than one year & 26 & $10.12 \%$ \\
Using electronic business platform & $1-3$ years & 93 & $36.19 \%$ \\
shopping years & More than 3 years & 138 & $53.7 \%$ \\
\hline
\end{tabular}

Table 2. E-commerce Internet consumer financial products use situation table.

\begin{tabular}{cccc}
\hline Features & Type & Sample number (unit) & Percentage \\
\hline \multirow{3}{*}{ Length of use } & $3-6$ months & 163 & 63.42 \\
& 6 - 12 months & 34 & 13.23 \\
& More than 1 years & 36 & 14.01 \\
The amount of Use & 2400 yuan & 167 & 9.34 \\
& $500-1000$ yuan & 28 & 64.98 \\
& 1000 - 3000 yuan & 29 & 10.89 \\
& More than 3000 yuan & 33 & 11.28 \\
\hline
\end{tabular}

for $64.98 \%$. This partly reflects the college students' attempts to consume financial products, and the consumer financial market of college students is still in the initial stage.

\subsection{Reliability and Validity Analysis}

In this study, we used SPSS 18.0 to analyze the Cronbach's alpha coefficient of the related variables to test the reliability of the questionnaire. The results are shown in Table 3. The value of Cronbach's alpha coefficient of each variable in the questionnaire was above 0.8 , which indicates that the survey sample has passed the test of internal consistency.

This study mainly analyzes the content validity and structure validity of the questionnaire. This research questionnaire is based on the maturity scale of predecessors and is completed under the guidance of the tutor. Therefore, this paper 
Table 3. The Cronbach's alpha value of each variable factor.

\begin{tabular}{ccc}
\hline Variable & Cronbach's Alpha & N of Items \\
\hline Subjective norm & 0.88 & 4 \\
Consumer innovativeness & 0.87 & 4 \\
Perceived ease of use & 0.95 & 4 \\
Perceived usefulness & 0.90 & 5 \\
Perceived risk & 0.90 & 5 \\
Usage Intention & 0.92 & 3 \\
\hline
\end{tabular}

has good content validity. This study used SPSS18.0 to analyze the structural validity of the questionnaire. The data show that the KMO value $=0.79>0.7$, and the significance of the Bartlett's spherical test $p=0.000<0.01$, indicating that this statistical data is suitable for factor analysis. Then, the principal component factor analysis of the data was analyzed, and the factor with eigenvalue greater than 1 was extracted. As shown in Table 4, the common factors extracted in this study all contain the indicators that the load is greater than 0.6. This shows that the items are reasonable and the reliability is good, and that the extracted factor can better explain the measured results. And the explanatory variance is more than $70 \%$, indicating that the questionnaire can basically cover most of the original measurement indicators and has good structural validity.

\subsection{Structural Equation Model Analysis}

In this paper, we use AMOS 17 to fit the model, test the relationship between variables and the hypothesis, and judge the significance and prediction ability of the theoretical model. The results of the fitting index of the structural equation model are shown in Table 5, and the ratio of the chi-square to the degree of freedom is 2.40 , which is less than the recommended standard of 3 , indicating that the model fitting degree is good. The other fitting values can also meet the recommended standard values, so the overall model fits well.

1) Hypothesis testing

The results of the hypothesis test of the modified model are shown in Table 6, and the path coefficients obtained are shown in Figure 1.

After data processing and model modification, 7 of the 10 hypotheses proposed in this study have all been validated.

As shown in Table 6, the effect of perceived usefulness on the Usage Intention was $0.58(p<0.001)$, and the effect of perceived ease of use on perceived usefulness was $0.70(p<0.001)$. It can be seen that perceived usefulness directly and significantly affects the willingness to use. However, this article does not verify the direct impact of perceived ease of use on the willingness to use, but indirectly enhances the intention to use by enhancing the perceived usefulness of consumers. H1a and H1c are validated. 
Table 4. Validity analysis of questionnaire.

\begin{tabular}{|c|c|c|c|c|}
\hline Variable & $\begin{array}{l}\text { Item } \\
\text { number }\end{array}$ & $\begin{array}{l}\text { Factor } \\
\text { Loading }\end{array}$ & $\begin{array}{c}\text { Common Factor } \\
\text { variance }\end{array}$ & $\begin{array}{c}\text { Total variance } \\
\text { explained }\end{array}$ \\
\hline \multirow{5}{*}{ Perceived ease of use } & PE2 & 0.96 & 0.92 & \multirow{5}{*}{$87.98 \%$} \\
\hline & PE1 & 0.94 & 0.88 & \\
\hline & & & & \\
\hline & PE3 & 0.92 & 0.84 & \\
\hline & PE4 & 0.94 & 0.88 & \\
\hline \multirow{5}{*}{ Perceived risk } & FR1 & 0.81 & 0.65 & \multirow{6}{*}{$72.63 \%$} \\
\hline & FR2 & 0.86 & 0.74 & \\
\hline & FR3 & 0.82 & 0.66 & \\
\hline & PR1 & 0.91 & 0.82 & \\
\hline & PR2 & 0.87 & 0.76 & \\
\hline \multirow{4}{*}{ Consumer innovativeness } & PI4 & 0.84 & 0.89 & \\
\hline & PI3 & 0.84 & 0.88 & \multirow{3}{*}{$72.62 \%$} \\
\hline & PI2 & 0.81 & 0.86 & \\
\hline & PI1 & 0.76 & 0.77 & \\
\hline \multirow{4}{*}{ Perceived usefulness } & PU2 & 0.85 & 0.89 & \multirow{4}{*}{$76.94 \%$} \\
\hline & PU1 & 0.82 & 0.91 & \\
\hline & PU4 & 0.71 & 0.88 & \\
\hline & PU3 & 0.60 & 0.83 & \\
\hline \multirow{4}{*}{ Subjective norm } & SN1 & 0.65 & 0.81 & \multirow{4}{*}{$72.97 \%$} \\
\hline & $\mathrm{SN} 2$ & 0.71 & 0.85 & \\
\hline & SN3 & 0.80 & 0.89 & \\
\hline & $\mathrm{SN} 4$ & 0.76 & 0.87 & \\
\hline \multirow{3}{*}{ Usage Intention } & BI1 & 0.92 & 0.84 & \multirow{3}{*}{$85.62 \%$} \\
\hline & BI2 & 0.95 & 0.90 & \\
\hline & BI3 & 0.91 & 0.83 & \\
\hline
\end{tabular}

Table 5. Test results of fitting degree of structural equation model.

\begin{tabular}{cccccccccc}
\hline & $\begin{array}{c}\text { Absolute } \\
\text { fitness index }\end{array}$ & & Value added fitness index & & $\begin{array}{c}\text { Parsimony } \\
\text { fitness index }\end{array}$ \\
\hline $\begin{array}{c}\text { Statistical test } \\
\text { quantity }\end{array}$ & /d.f. & RMSEA & RFI & IFI & CFI & TLI & NFI & PNFI & PCFI \\
$\begin{array}{c}\text { Model fitting } \\
\text { Result }\end{array}$ & 2.40 & 0.07 & 0.89 & 0.94 & 0.94 & 0.93 & 0.90 & 0.77 & 0.80 \\
$\begin{array}{c}\text { evaluation } \\
\text { criterion }\end{array}$ & $<3.0$ & $<0.08$ & $>0.9$ & $>0.9$ & $>0.9$ & $>0.9$ & $>0.9$ & $>0.5$ & $>0.5$ \\
$\begin{array}{c}\text { Evaluation } \\
\text { result }\end{array}$ & satisfy & satisfy & passable & satisfy & satisfy & satisfy & satisfy & satisfy & satisfy \\
\hline
\end{tabular}


Table 6. Estimation results of initial structural model.

\begin{tabular}{|c|c|c|c|c|c|}
\hline Research hypothesis & Path relation & Standardized path coefficient & $\mathrm{T}$ & $P$ & Test Result \\
\hline H1a & Usage Intention <--- Perceived usefulness & 0.58 & 9.76 & $* * *$ & establish \\
\hline $\mathrm{H} 1 \mathrm{c}$ & Perceived usefulness <--- Perceived ease of use & 0.70 & 11.25 & $* * *$ & establish \\
\hline $\mathrm{H} 2 \mathrm{a}$ & Usage Intention <--- Perceived risk & -0.10 & -2.21 & 0.03 & establish \\
\hline $\mathrm{H} 3 \mathrm{a}$ & Usage Intention <--- Subjective norm & 0.36 & 6.23 & $* * *$ & establish \\
\hline $\mathrm{H} 3 \mathrm{~b}$ & Perceived usefulness <--- Subjective norm & 0.26 & 4.80 & $* * *$ & establish \\
\hline $\mathrm{H} 4 \mathrm{a}$ & Perceived ease of use $<---$ Consumer innovativeness & 0.39 & 5.29 & $* * *$ & establish \\
\hline $\mathrm{H} 4 \mathrm{c}$ & Perceived risk <--- Consumer innovativeness & -0.17 & -2.79 & 0.010 & establish \\
\hline
\end{tabular}

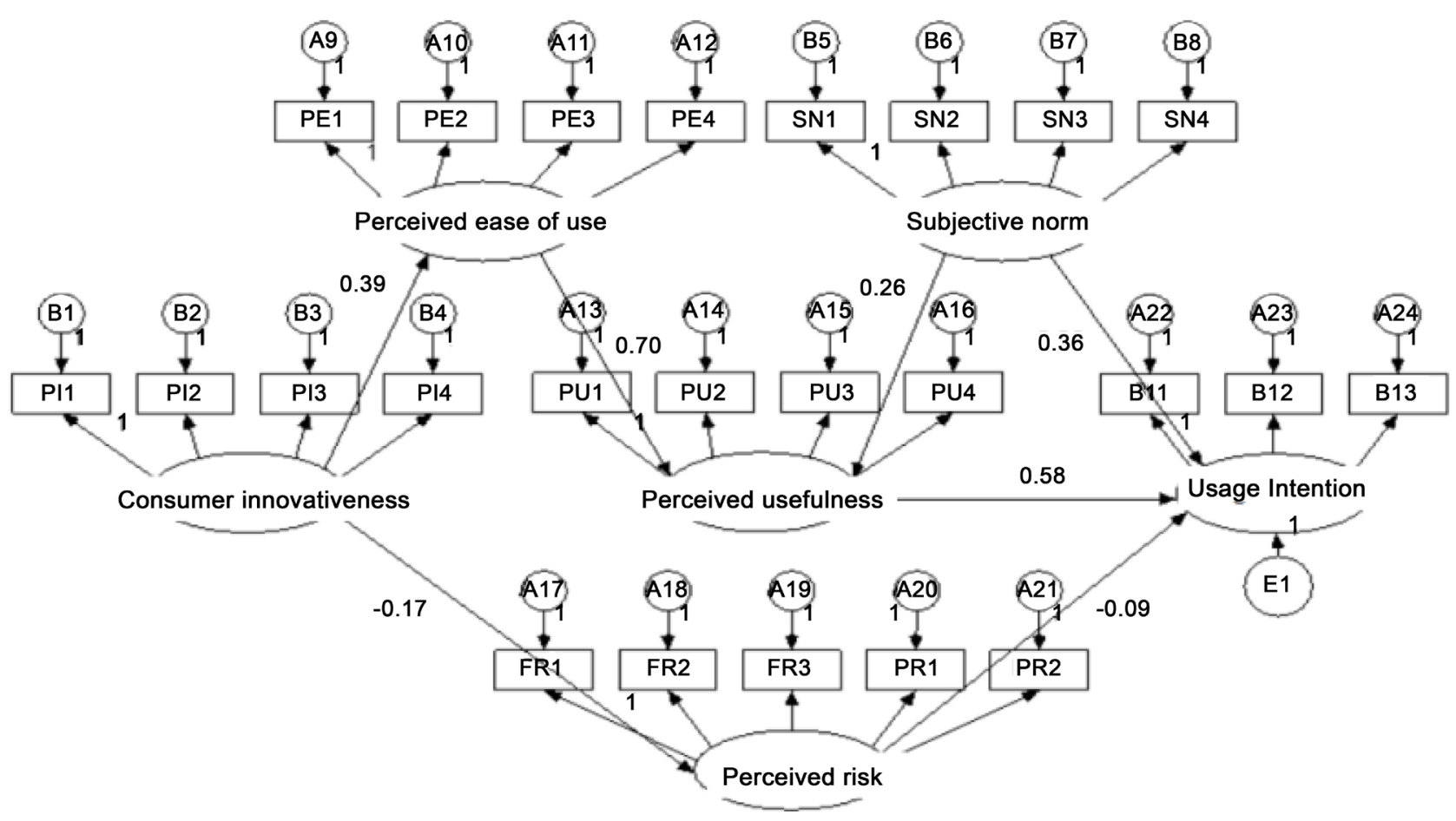

Figure 1. Path coefficient diagram of structural equation model.

The effect of perceived risk on willingness to use is $-0.10(p<0.05)$. It can be seen that perceived risk can have a certain impact on willingness to use, that is, the higher the perceived risk, the lower the willingness to use. H2a is verified.

The effect of subjective norms on the willingness to use was $0.36(p<0.001)$, and the effect of subjective norms on perceived usefulness was 0.26 (9.001). In the technology acceptance model 2, subjective norms as social influence variables explain the influence of perceived usefulness on the willingness to use. And the results of this study are validated again. H3a and H3b are verified.

The effect of consumer innovativeness on perceived ease of use was 0.39 ( $p<$ 0.001 ), and the effect of consumer innovativeness on perceived risk was 0.17 ( $p<$ 0.01 ), indicating that the higher the innovativeness of consumers, the higher the perceived ease of use of products, and the lower the perceived risk. $\mathrm{H} 4 \mathrm{a}$ and $\mathrm{H} 4 \mathrm{c}$ are verified. 
$\mathrm{H} 1 \mathrm{~b}, \mathrm{H} 2 \mathrm{~b}, \mathrm{H} 4 \mathrm{~b}$ have not been verified. $\mathrm{H} 1 \mathrm{~b}$ suggests that perceived ease of use has a positive effect on the willingness to use. H2b suggests that perceived usefulness has a positive effect on perceived risk. H4b proposes that perceived usefulness has a positive impact on consumer innovation. None of the three assumptions are supported.

\section{Conclusions}

\subsection{Research Conclusions}

This study takes two representative Internet consumer financial products, "Jingdong baitiao" and "Ant check later" as examples, and empirically analyzes the influencing factors that affect consumers' willingness to use. This research has made a beneficial exploration in explaining and predicting consumer's willingness to adopt Internet consumer financial products, and verified the validity of the research model and modified the research hypothesis from an empirical point of view. The main conclusions of this paper are as follows:

Conclusion 1: Perceived usefulness has a significant positive effect on the willingness to use, and perceived ease of use has a significant positive effect on perceived usefulness.

Conclusion 2: Perceived risk has a significant negative impact on the willingness to use.

Conclusion 3: The subjective norms have a significant positive effect on the willingness to use, subjective norms have a significant positive impact on the perceived usefulness.

Conclusion 4: Consumer innovativeness has a significant positive impact on perceived ease of use, and consumer innovation has a significant negative impact on perceived risk.

\subsection{Marketing Implications}

Based on the empirical results of this paper, we can make the following suggestions for Internet consumer financial enterprises:

1) Enterprises should start from the needs of customers, deeply cultivate users' needs and meet the demand. For example, different products can be introduced according to the needs of people of different age groups, providing added valueadded services for products and so on.

2) Pay attention to network security, prevent transaction risk and reduce user's perceived risk. Internet consumer finance enterprises should perfect the protection mechanism of consumer personal information. By means of technical means, the perceived risk of consumers can be controlled in the range that they can bear, thus increasing the willingness to use. For example, multiple validations are used in login and registration to enhance user security.

3) Internet consumer financial companies should also vigorously promote and guide consumers to change their concept of consumption, so that consumers accept the "first consumption, after payment" approach and develop their interest 
and habit of using the Internet to consume financial products. For example, it can be used in the form of embedded TV advertisement, so that the audience can naturally be influenced by this consumption concept in the plot.

4) To promote new business to innovative and high-priority consumers, through the survey found that more innovative consumers with higher willingness to use. Therefore, enterprises can use big data analysis to make accurate marketing of such users and give priority to promotion.

\subsection{Research Limitations and Prospects}

Although some achievements have been made in this study, there are still many deficiencies and shortcomings. According to the shortcomings of this article, the future research can also be considered from the following aspects.

1) Sample limitations. The economic culture and consumption habits of different regions of China are quite different. Future studies can expand the scope and sample size of the sample to increase the interpretation of the study.

2) Limitations of research methods. This study mainly uses the method of questionnaire to obtain the data, then carries on the statistical analysis to reach the final conclusion. Future research can be combined with a variety of methods of investigation, such as interview.

3) Limitations of measurement dimension. This article puts forward five factors that affect the willingness of university students to use Internet consumer financial products, but can not fully explain. There are still many factors that affect college students' willingness to adopt. Future research can increase the measurement dimension by integrating more domestic and foreign literature to enhance its interpretation.

\section{References}

Ajzen, I. (1985). From Intentions to Actions: A Theory of Planned Behavior. Action Control. Springer Berlin Heidelberg, 11-39.

Ajzen, I. (1991). The Theory of Planned Behavior, Organizational Behavior and Human Decision Processes. Organizational Behavior and Human Decision Processes, 50, 179-211. https://doi.org/10.1016/0749-5978(91)90020-T

Bauer, R. A. (1960). Consumer Behavior as Risk Taking. In D. Cox (Ed.), Risk Taking and Information Handling in Consumer Behavior (pp. 389-398). Cambridge, MA: Harvard University Press.

Chen, W. P. (2011). Life Style, Consumer Innovation and New Product Purchase Behavior Relationship. Economic Management, 2, 94-101.

Davis, F. D. (1989). Perceived Usefulness, Perceived Ease of Use, and User Acceptance of Information Technology. MIS Quarterly, 13, 319-340. https://doi.org/10.2307/249008

Deng Z. W., \& Lu Y. B. (2007). Empirical Analysis and Comparison of Service Adoption Model of Mobile Banking. Industrial Engineering and Management, 6, 59-65.

Featherman, M. S., \& Pavlou, P. A. (2003). Predicting E-Services Adoption: A Perceived Risk Facets Perspective. International Journal of Human-Computer Studies, 59, 451-474. https://doi.org/10.1016/S1071-5819(03)00111-3 
Fishbein, M. (1963). An Investigation of the Relationship between Beliefs about an Object and the Attitude toward That Object. Current Opinion in Investigational Drugs, 16, 233-239. https://doi.org/10.1177/001872676301600302

Fishbein, M., \& Ajzen, I. (1975). Belief, Attitude, Intention, Behavior: An Introduction to Theory and Research. Reading, MA: Addison Wesley.

Hofstede, F, T., \& Wedel, M. (1999). A Cross-National Investigation into the Individual and National Cultural Antecedents of Consumer Innovativeness. Journal of Marketing, 63, 55-69. https://doi.org/10.2307/1251945

Huang, H., Liu, L., \& Wang, J. J. (2008). TAM-Based Mobile Content Service Adoption Analysis. Nankai Management Review, 11, 42-47.

Jacoby, J., \& Kaplan, L. B. (1972). The Components of Perceived Risk. Advances in Consumer Research, 3, 382-383.

Klopping, I. M., \& Kiuney, E. M. (2004). Extending the Technology Acceptance Model and the Task-Technology Fit Model Information Technology. Learning and Performance Journal, 22, 35-45.

Kotler, P. (2000). Marketing Management the Millennium Edition. London Prentice Hall International Inc.

Lederer, A. L., Maupin, D. J., Sena, M. P., \& Zhang, Y. (2000). The Technology Acceptance Model and the World Wide Web. Decision Support Systems, 29, 269-282. https://doi.org/10.1016/S0167-9236(00)00076-2

Liu, D. (2011). International Comparison of Consumer Finance Development Modes and References. Journal of Central University of Finance and Economics, No. 1, 27-43.

Liu, S. L. (2011). Structural Measurement of Consumers Innovativeness and the Impact on Innovative Behavior. Commercial Economy and Management, No. 233, 81-90.

Midgley, D, F., \& Dowling, G. R. (1978). Innovativeness: The Concept and Its Measurement. Journal of Consumer Research, 4, 229-242. https://doi.org/10.1086/208701

Park, J., Lee, D., \& Ahn, J. (2004). Risk-Focused E-Commerce Adoption Model: A Cross-Country Study. Journal of Global Information Technology Management, 7, 6-30. https://doi.org/10.1080/1097198X.2004.10856370

Rogers, E. M., \& Shoemaker, F. F. (1971). Communication of Innovations; $A$ Cross-Cultural Approach (Vol. 9, p. 476). New York, NY: Free Press.

Venkatesh, V., \& Davis, F. D. (2000). A Theoretical Extension of the Technology Acceptance Model: Four Longitudinal Field Studies. Management Science, 46, 186-204.

https://doi.org/10.1287/mnsc.46.2.186.11926

Wang, J., Liao, L., \& Zhang, J. B. (2010). A Review of Consumer Finance Research (pp. 5-29). Economic Research.

Xu, C. J., Wang, Y. Y., \& Huang, P. (2011). Study on College Students' Mobile Internet Access from the Perspective of TAM Model. Modern Educational Technology, 21, 97-102. 